Western University

Scholarship@Western

$10-1-2011$

\title{
Chronic obstructive pulmonary disease: Quantification of bronchodilator effects by using hyperpolarized ${ }^{3} \mathrm{He}$ MR imaging
}

Miranda Kirby

Lindsay Mathew

Mohammadreza Heydarian

Roya Etemad-Rezai

David G McCormack

See next page for additional authors

Follow this and additional works at: https://ir.lib.uwo.ca/biophysicspub

Part of the Medical Biophysics Commons

\section{Citation of this paper:}

Kirby, Miranda; Mathew, Lindsay; Heydarian, Mohammadreza; Etemad-Rezai, Roya; McCormack, David G; and Parraga, Grace, "Chronic obstructive pulmonary disease: Quantification of bronchodilator effects by using hyperpolarized "3e MR imaging" (2011). Medical Biophysics Publications. 145.

https://ir.lib.uwo.ca/biophysicspub/145 


\section{Authors}

Miranda Kirby, Lindsay Mathew, Mohammadreza Heydarian, Roya Etemad-Rezai, David G McCormack, and Grace Parraga 


\section{Chronic Obstructive Pulmonary} Disease: Quantification of

\section{Bronchodilator Effects by Using Hyperpolarized ${ }^{3} \mathrm{He}$ MR Imaging'}

Miranda Kirby, BSc

Lindsay Mathew, PhD

Mohammadreza Heydarian, PhD

Roya Etemad-Rezai, MD, FRCPC

David G. McCormack, MD, FRCPC

Grace Parraga, PhD
Purpose:

Materials and Methods:

Results:

Conclusion:
To evaluate short-acting bronchodilator effects in chronic obstructive pulmonary disease (COPD) by using hyperpolarized helium $3\left({ }^{3} \mathrm{He}\right)$ magnetic resonance (MR) imaging, spirometry, and plethysmography.

Fourteen ex-smokers with COPD provided written informed consent to a local ethics board-approved and Health Insurance and Portability Accountability Act-compliant protocol and underwent hyperpolarized ${ }^{3} \mathrm{He}$ and hydrogen $1 \mathrm{MR}$ imaging, spirometry, and plethysmography before and a mean of 25 minutes \pm 2 (standard deviation) after administration of $400 \mu \mathrm{g}$ salbutamol. Distribution of ${ }^{3} \mathrm{He}$ gas was evaluated by using semiautomated segmentation of ${ }^{3} \mathrm{He}$ voxel intensities, where cluster 1 represented regions of signal void or ventilation defect volume (VDV), and clusters 2-5 (C2-C5) represented gradations of signal intensity from hypointensity (C2) to hyperintensity (C5). ${ }^{3} \mathrm{He}$ ventilation defect percentage (VDP) was calculated as VDV normalized to the thoracic cavity volume. Comparisons of pre- and post-salbutamol means were performed by using a two-way mixed-design repeated measures analysis of variance, and comparisons of the magnitude of the treatment effect between pulmonary function and ${ }^{3} \mathrm{He}$ MR imaging measurements were performed by using effect size (ES) calculations. The relationships between pulmonary function and ${ }^{3} \mathrm{He}$ MR imaging findings were determined by using Spearman correlation coefficients.

After salbutamol administration, there were significant changes in forced expiratory volume in 1 second $\left(\mathrm{FEV}_{1}\right)(P=.001)$, total lung capacity $(P=.04)$, and functional residual capacity $(P=.03)$, as well as VDP $(P<.0001)$ and ${ }^{3} \mathrm{He}$ gas distribution $(\mathrm{C} 2, P=.01$; C3, $P=.03$; C4, $P<.0001$; and C5, $P=.02)$. Treatment ES was greater for ${ }^{3} \mathrm{He}$ VDP than for $\mathrm{FEV}_{1}$ (0.50 vs 0.22$)$. There was a significant correlation between baseline VDP and post-salbutamol FEV 1 change $(r=-0.77, P=.001)$. Although five patients were classified as bronchodilator responders and nine patients were classified as bronchodilator nonresponders according to American Thoracic Society and European Respiratory Society criteria, there was no significant difference in the magnitude of the ${ }^{3} \mathrm{He}$ MR imaging changes after salbutamol administration between responder groups. revision received April 17; accepted May 17; final. version accepted May 20. Supported by Canadian Institutes of Health Operating Grant MOP \#97748 and Team Grant FRN \#97687. M.K. supported by the Natural Sciences and Engineering Research Council of Canada; Canadian Institutes of Health Research (CIHR) Strategic Training Program; L.M. supported by the CIHR Vanier Scholarship Program and the Schulich Graduate Scholarship of the University of Western Ontario. G.P. supported by a CIHR New Investigator Award. Address correspondence to G.P. (e-mail: gep @imaging.robarts.ca).

○ RSNA, 2011
${ }^{3} \mathrm{He}$ MR imaging depicted significant improvements in the distribution of ${ }^{3} \mathrm{He}$ gas after bronchodilator therapy in ex-smokers with COPD with and those without clinically important changes in $\mathrm{FEV}_{1}$.

${ }^{\circ}$ RSNA, 2011

Supplemental material: http://radiology.rsna.org/lookup/suppl /doi:10.1148/radiol.11110403/-/DC1 
C hronic obstructive pulmonary disease (COPD) is characterized by progressive expiratory flow limitation that develops because of the combined effects of large and small airway dysfunction and increased lung compliance related to the permanent destructive changes of emphysema (1). Gas trapping and dynamic lung hyperinflation are major consequences of decreased expiratory airflow and often lead to many of the disabling symptoms associated with COPD, such as dyspnea and limitation of exercise capacity $(2,3)$. After smoking cessation, bronchodilators are the first-line therapy in the symptomatic management of COPD (3), and assessment of acute response to bronchodilators is often based on spirometric measurements of forced expiratory volume in 1 second $\left(\mathrm{FEV}_{1}\right)$. Although spirometric measurements provide the most common primary end point for clinical trials evaluating therapeutic response, relatively poor correlations have been reported between $\mathrm{FEV}_{1}$ and other clinical measurements of COPD (4-6). In other words, symptomatic relief after bronchodilator use often occurs with only modest improvements in $\mathrm{FEV}_{1}$ (7-9), underscoring the apparent discordance between spirometric measurements and COPD symptoms, quality of life, and functional measurements.

The discordance between spirometric measurements and COPD symptoms,

\section{Advances in Knowledge}

- Helium $3\left({ }^{3} \mathrm{He}\right) \mathrm{MR}$ imaging measurements of gas distribution showed significant improvements $(P<.0001)$ after salbutamol administration in ex-smokers with chronic obstructive pulmonary disease (COPD), providing evidence of the regional and physiologic effects of therapy.

- Significant improvements $(P<$ $.0001)$ in ${ }^{3} \mathrm{He}$ gas distribution after bronchodilator administration were detected by using hyperpolarized ${ }^{3} \mathrm{He} \mathrm{MR}$ imaging in COPD, regardless of spirometrybased bronchodilator response classification. as well as the limitation of standard measures of expiratory airflow for evaluating the regional nature of bronchodilator response, is motivating the evaluation of new methods $(10,11)$, including those based on noninvasive imaging (12-15). For example, computed tomography (CT) has been used to evaluate changes in airway morphology after administration of salbutamol $(12,13)$ and tiotropium $(14,15)$ and showed greater post-bronchodilator response in patients with COPD with mainly airway disease compared with those with mainly emphysema (16). Additionally, a recent single photon emission computed tomography/CT and multiple breath nitrogen washout study (17) reported no significant change in ventilation heterogeneity after tiotropium administration.

Pulmonary magnetic resonance (MR) imaging with hyperpolarized helium 3 ( ${ }^{3} \mathrm{He}$ ) has emerged as a functional imaging method that provides high-spatialresolution and high-temporal-resolution (18-23) images of the lung. Regional ventilation abnormalities are clearly visualized as areas of decreased ${ }^{3} \mathrm{He}$ signal in the lung that can be scored or quantified with the metric ventilation defect percentage (VDP) (19) or percentage ventilated volume (24). ${ }^{3} \mathrm{He} \mathrm{MR}$ imaging ventilation abnormalities have previously been evaluated in COPD (25-30) with measurements that are sensitive to the pathologic changes that accompany COPD (24), have high same-day and short-term reproducibility $(20,21)$, and reveal significant longitudinal changes over 2 years before changes in $\mathrm{FEV}_{1}$ are observed (18). Because of previous reproducibility $(20,21)$ and longitudinal (18) findings, we hypothesized that ${ }^{3} \mathrm{He}$

\section{Implication for Patient Care}

- Our results indicate that significant gas distribution improvements occur even in patients with COPD with minimal forced expiratory volume in 1 second or forced vital capacity response to salbutamol; these findings are relevant to our understanding of the regional and functional effects of bronchodilators.
MR imaging would provide the necessary and sufficient spatial and temporal sensitivity, as well as precision, to depict any potential regional functional lung changes after bronchodilator therapy. Therefore, our aim was to evaluate short-acting bronchodilator effects in COPD by using hyperpolarized ${ }^{3} \mathrm{He}$ MR imaging, spirometry, and plethysmography.

\section{Materials and Methods}

\section{Patients}

All patients provided written informed consent to the study protocol, which was approved by the local research ethics board and Health Canada, and the study was compliant with the Personal Information Protection and Electronic Documents Act of Canada and the Health Insurance Portability and Accountability Act of the United States. The use of an on-site ${ }^{3} \mathrm{He}$ gas polarizer (HeliSpin; GE Healthcare, Durham, NC)

Published online before print

10.1148/radiol.11110403 Content code: $\mathrm{CH}$

Radiology 2011; 261:283-292

\section{Abbreviations:}

ATS = American Thoracic Society

$\mathrm{COPD}=$ chronic obstructive pulmonary disease

$\mathrm{D} L \mathrm{CO}=$ diffusing capacity of lung for carbon monoxide

ES = effect size

$\mathrm{FEV}_{1}=$ forced expiratory volume in 1 second

$\mathrm{FRC}=$ functional residual capacity

$\mathrm{FVC}=$ forced vital capacity

GOLD = Global Initiative for Chronic Obstructive Lung

Disease

$\mathrm{SaO}_{2}=$ arterial oxygen saturation

$\mathrm{SDD}=$ smallest detectable difference

TLC $=$ total lung capacity

VDP $=$ ventilation defect percentage

VDV $=$ ventilation defect volume

\section{Author contributions:}

Guarantors of integrity of entire study, R.E., D.G.M., G.P.; study concepts/study design or data acquisition or data analysis/interpretation, all authors; manuscript drafting or manuscript revision for important intellectual content, all authors; manuscript final version approval, all authors; literature research, M.K., M.H., G.P.; clinical studies, M.K., L.M., R.E., D.G.M., G.P.; statistical analysis, M.K., L.M., G.P.; and manuscript editing, all authors

Potential conflicts of interest are listed at the end of this article. 
was provided to Robarts Research Institute through an agreement with GE Healthcare for which we pay $\$ 100000$ Canadian annually.

Fourteen patients with a clinical diagnosis of COPD who were ex-smokers with a smoking history of at least 10 pack-years and who had Global Initiative for Chronic Obstructive Lung Disease (GOLD) stage II-IV disease were enrolled. Patients were required to refrain from using both short-acting and longacting bronchodilators on the morning of the study. Prebronchodilator MR imaging was performed immediately after pulmonary function testing; postbronchodilator MR imaging and pulmonary function testing were performed a mean of 25 minutes \pm 2 (standard deviation) after administration of $400 \mu \mathrm{g}$ salbutamol sulfate USP (Apo-Salvent CFC Free Inhalation Aerosol; Apotex, Toronto, Ontario, Canada), which was inhaled by using a spacer device.

\section{Pulmonary Function Testing}

Spirometry was performed using an EasyOne spirometer (ndd Medizintechnik, Zurich, Switzerland) according to the American Thoracic Society (ATS) guidelines. Static lung volumes and diffusing capacity of lung for carbon monoxide (DLCO) were measured by using body plethysmography (MedGraphics, St Paul, Minn).

\section{Image Acquisition}

MR imaging was performed with a wholebody 3.0-T MR imaging system (Excite 12.0; GE Healthcare, Milwaukee, Wis) with broadband imaging capability as previously described (21), and ${ }^{3} \mathrm{He}$ MR imaging was enabled by using a singlechannel rigid elliptical transmit-receive chest coil (RAPID Biomedical, Wuerzburg, Germany). It is important to note that we endeavored to minimize the potential for differences in the levels of inspiration between the breath-hold acquisitions for each patient by (a) conducting training and practice sessions for all patients before MR imaging related to the inspiration breath-hold maneuver from functional residual capacity (FRC) and (b) continuous coaching and monitoring at the MR imaging table by a pulmonary function technologist during all inspiration breath-hold acquisitions. Because of this extensive coaching, no correction for differences in inspiration levels between breath-hold acquisitions for individual patients was required. Pulse oximetry was used to measure arterial oxygen saturation $\left(\mathrm{SaO}_{2}\right)$ for all patients during imaging sessions; an adverse event was considered to have occurred when $\mathrm{SaO}_{2}$ decreased below 88\% at any time during the imaging session. Study withdrawal was required when $\mathrm{SaO}_{2}$ decreased to $80 \%$ for 10 seconds or longer.

Conventional hydrogen $1\left({ }^{1} \mathrm{H}\right) \mathrm{MR}$ imaging was performed before hyperpolarized ${ }^{3} \mathrm{He} \mathrm{MR}$ imaging, with patients imaged during a 1.0-L breath-hold of ${ }^{4} \mathrm{He} /$ nitrogen $2\left(\mathrm{~N}_{2}\right)$ by using a wholebody radiofrequency coil and a ${ }^{1} \mathrm{H}$ fast spoiled gradient-recalled echo sequence (total data acquisition time, 16 seconds; repetition time msec/echo time msec, 4.7/1.2; flip angle, $30^{\circ}$; field of view, $40 \times 40 \mathrm{~cm}$; matrix, $256 \times 128$; 14 sections; $15-\mathrm{mm}$ section thickness; no gap), as previously described (21).

Prior to ${ }^{3} \mathrm{He} \mathrm{MR}$ imaging, a polarizer system (HeliSpin; GE Healthcare) was used to polarize ${ }^{3} \mathrm{He}$ gas to $30 \%-40 \%$, and doses of $5 \mathrm{~mL}$ per kilogram of body weight, diluted with ultra-high purity medical-grade nitrogen (Spectra Gases, Alpha, NJ), were administered in 1.0-L Tedlar bags. As previously described (21), hyperpolarized ${ }^{3} \mathrm{He}$ coronal static ventilation images were acquired during a breath-hold of a $1.0-\mathrm{L}^{3} \mathrm{He} / \mathrm{N}_{2}$ mixture (total data acquisition time, 14 seconds; $4.3 / 1.4$; flip angle, $7^{\circ}$; bandwidth, $31.25 \mathrm{kHz}$; field of view, $40 \times 40 \mathrm{~cm}$; matrix, $128 \times 128$; 14 sections; $15-\mathrm{mm}$ section thickness; no gap).

\section{Image Analysis}

Semiautomated segmentation of ${ }^{3} \mathrm{He}$ pulmonary ventilation MR images was performed by using custom software that had been generated by using MATLAB R2007b (Mathworks, Natick, Mass), as previously described (31). Briefly, and as shown in the schematic in Figure 1, ${ }^{3} \mathrm{He}$ MR images were evaluated by using k-means cluster analysis (32), similar to previously described methods for ${ }^{3} \mathrm{He}$
MR image segmentation (33-35), to classify the ${ }^{3} \mathrm{He}$ MR imaging voxel intensity values into clusters ranging from 1 to 5 , representing gradations of signal intensity from no signal (cluster 1) and hypointense signal (cluster 2) to hyperintense signal (cluster 5) and generating a ${ }^{3} \mathrm{He}$ voxel cluster map (Fig 1b). To obtain the external contour of the thoracic cavity to differentiate ventilation defects (cluster 1) from the edge of the lung, ${ }^{1} \mathrm{H}$ MR images were segmented by using a seeded region-growing algorithm (36) and were registered to the ${ }^{3} \mathrm{He} \mathrm{MR}$ ventilation images as previously described (37). VDP was generated by using VDV, or cluster 1 , normalized to the thoracic cavity volume as previously described (19). For the remaining ventilation clusters, the segmented ${ }^{1} \mathrm{H}$ thoracic cavity volume was used to generate a cluster percentage representing a normalized ${ }^{3} \mathrm{He}$ cluster volume for the lung. All measurements were performed by the same observer (M.K., with 3 years of experience performing manual ${ }^{3} \mathrm{He} \mathrm{MR}$ image segmentation and 1 year of experience developing and performing semiautomated ${ }^{3} \mathrm{He}$ MR image segmentation), who was blinded to patient and time point, with time point randomized to reduce any potential measurement bias. Reproducibility of the semiautomated method was determined on the basis of the pre-salbutamol intraobserver variability of five repeated measurements for five patients with COPD. The smallest detectable difference (SDD), or the minimum change in ${ }^{3} \mathrm{He}$ measurements that could be measured confidently in individual patients - not due to observer measurement variability, for five of the patients with COPD was $2 \%$ for VDP and $0.4 \%, 1 \%, 0.6 \%$, and $0.3 \%$ for clusters $2-5$, respectively.

\section{Statistical Analysis}

Multivariate analysis of variance and repeated-measures analysis of variance were performed for comparison of preand post-salbutamol pulmonary function and lung volume measurements by using software (SPSS, version 16.0; SPSS, Chicago, Ill). A two-way mixed-design analysis of variance was used (with SPSS) to determine the interactions between 


\section{Figure 1}

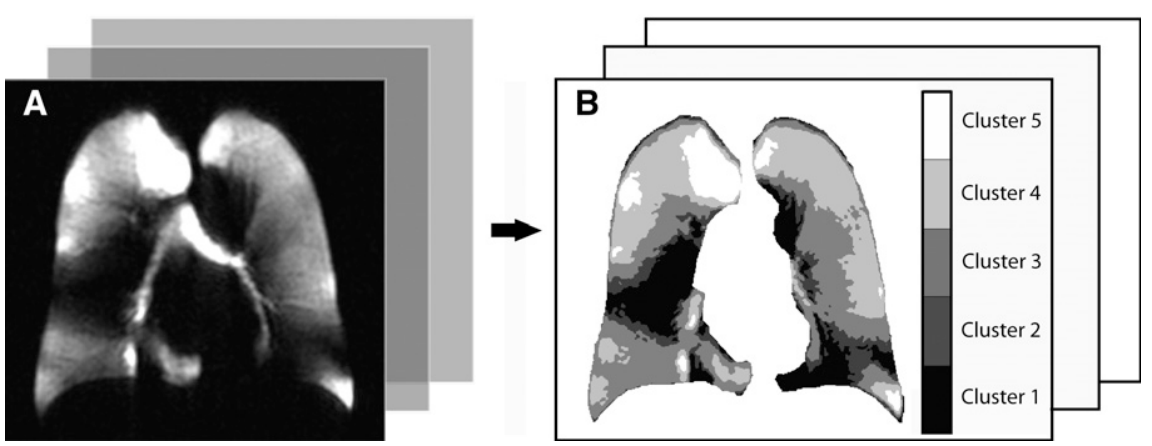

Figure 1: $\quad A$, Coronal ${ }^{3} \mathrm{He} \mathrm{MR}$ image and, $B,{ }^{3} \mathrm{He}$ cluster map generated with semiautomated cluster analysis and segmentation for all sections. ${ }^{3} \mathrm{He}$ ventilation defect volume (VDV) $=$ cluster 1 , while VDP $=$ cluster 1 normalized to thoracic cavity volume.

patients and treatment, imaging section and treatment, and bronchodilator response group and treatment for all ${ }^{3} \mathrm{He}$ MR imaging measurements. Effect size (ES) calculations allowed the magnitude of an effect to be compared between disparate types of measurements (38). Therefore, for comparison of the magnitude of the treatment effect between pulmonary function and imaging measurements, treatment ES was calculated as the ratio of the mean difference between pre- and post-salbutamol measurements and the pooled standard deviation for all patients, calculated by using Hedges $g$ as shown in Equation (1):

$$
g=\frac{\bar{x}_{\text {post }}-\bar{x}_{\text {pre }}}{\sqrt{\frac{\left(n_{\text {post }}-1\right) \mathrm{SD}_{\text {post }}^{2}+\left(n_{\text {pre }}-1\right) \mathrm{SD}_{\text {pre }}^{2}}{n_{\text {post }}+n_{\text {pre }}-2}}},
$$

where $\bar{x}_{\text {pre }}$ and $\bar{x}_{\text {post }}$ are the mean preand post-salbutamol measurement for all patients, $\mathrm{SD}_{\text {pre }}$ and $\mathrm{SD}_{\text {post }}$ are the standard deviations of the pre- and postsalbutamol measurements for all patients, and $n_{\text {pre }}$ and $n_{\text {post }}$ are the numbers of patients evaluated before and after salbutamol administration. The SDD, defined as the smallest difference that can be measured with prospectively determined confidence that is not due to measurement error (variability), was calculated for five repeated pre-salbutamol ${ }^{3} \mathrm{He}$ VDP measurements according to the method of Eliasziw et al (39), as shown in Equation (2):

$$
\mathrm{SDD} \geq z_{\alpha} \sqrt{2} \mathrm{SEM}_{\text {intra }},
$$

where $z_{\alpha}$ is 1.96 , corresponding to a significance level of $\alpha=.05$, and SEM $_{\text {intra }}$ is the standard error of measurement due to intraobserver variability and is calculated as shown in Equation (3):

$$
\mathrm{SEM}_{\mathrm{intra}}=\sqrt{\hat{\sigma}_{e}^{2}},
$$

where $\hat{\sigma}_{e}{ }^{2}$ is the intraobserver repeatedmeasures variance. Linear regression ( $r^{2}$ values) and Spearman correlation coefficients ( $r$ values) were calculated to determine the relationships between pulmonary function and ${ }^{3} \mathrm{He} \mathrm{MR}$ imaging measurements by using software (Prism, version 4.0; GraphPad Software, San Diego, Calif). In all statistical analyses, results were considered significant when the probability of making a type I error was less than $5 \%(P<.05)$.

\section{Results}

\section{Patient Demographics}

Patient demographic characteristics are provided in Table 1 for 14 ex-smokers with COPD (five with GOLD stage II disease, eight with GOLD stage III disease, and one with GOLD stage IV disease).

\section{Pulmonary Function Measurements}

Table 2 shows mean pulmonary function and ${ }^{3} \mathrm{He} \mathrm{MR}$ imaging measurements for all patients, and Table E1 (online), provides a per-patient list of all measurements. Statistically significant postsalbutamol changes were observed for $\mathrm{FEV}_{1}(P=.001, \mathrm{ES}=0.22)$, TLC $(P=.04, \mathrm{ES}=-0.34)$, and FRC $(P=.03$, $\mathrm{ES}=-0.10)$.

\section{Imaging Measurements}

Figure 2 shows two central coronal ${ }^{3} \mathrm{He}$ MR imaging sections, on which the trachea and two main bronchi are clearly visible and ${ }^{3} \mathrm{He}$ ventilation is displayed in red, registered to the gray-scale ${ }^{1} \mathrm{H} \mathrm{MR}$ images of the thorax for each of the five representative patients (two patients with GOLD stage II disease, two patients with GOLD stage III disease, and one patient with GOLD stage IV disease) before and after salbutamol administration. To ensure that the increased distribution of ${ }^{3} \mathrm{He}$ gas after salbutamol administration was not due to differences in the volume of polarized gas administered at each time point, we calculated the total pixel intensity for each lung image, including the trachea and major airways, from the image pixel intensity frequency histograms, as well as the total moles of polarized gas delivered for each patient time point (data not shown). These estimations showed that the amount of polarized gas administered and inhaled was not significantly different between time points $(P=.87)$. The signal-to-noise ratio for each pre- and post-salbutamol image pair was also not significantly different $(P=.12)$. To minimize the potential of introducing intensity variations because of $B_{1}$ field inhomogeneity, patients were located in the same position within the coil between imaging time points.

Table 2 shows mean normalized pre- and post-salbutamol ${ }^{3} \mathrm{He}$ measurements, and Table E2 (online) shows the mean pre- and post-salbutamol ${ }^{3} \mathrm{He}$ volume and signal intensity measurements. There was a significant decrease in VDP after salbutamol administration $(P<.0001, \mathrm{ES}=-0.50)$, and there was no relationship between post-salbutamol changes in VDP and image section 
Table 1

\section{Demographic Data in 14 Patients}

\begin{tabular}{|c|c|}
\hline Parameter & Datum \\
\hline Age $(y)$ & $70 \pm 6(61-77)$ \\
\hline Men & $70 \pm 6(61-77)$ \\
\hline Women & $71 \pm 6(64-77)$ \\
\hline No. of men & 8 \\
\hline Body mass index $\left(\mathrm{kg} / \mathrm{m}^{2}\right)$ & $24.9 \pm 3.8(17.6-31.4)$ \\
\hline $\mathrm{FEV}_{1}(\mathrm{~L})$ & $1.23 \pm 0.50(0.63-2.18)$ \\
\hline $\mathrm{FEV}_{1}^{*}$ & $45 \pm 12(28-61)$ \\
\hline FVC (L) & $2.98 \pm 0.83(1.52-4.44)$ \\
\hline $\mathrm{FVC}^{*}$ & $83 \pm 12(65-107)$ \\
\hline $\mathrm{FEV}_{1} / \mathrm{FVC}$ & $41 \pm 10(22-60)$ \\
\hline TLC (L) & $7.12 \pm 1.27(4.82-8.96)$ \\
\hline $\mathrm{TLC}^{*}$ & $122 \pm 20(101-175)$ \\
\hline Inspiratory capacity (L) & $2.21 \pm 0.54(1.39-3.09)$ \\
\hline Inspiratory capacity* & $83 \pm 16(58-108)$ \\
\hline FRC (L) & $4.89 \pm 1.22(3.14-7.27)$ \\
\hline $\mathrm{FRC}^{*}$ & $155 \pm 42(110-243)$ \\
\hline Reserve volume (L) & $3.83 \pm 0.94(2.63-5.25)$ \\
\hline Reserve volume* & $170 \pm 53(104-285)$ \\
\hline DLCO* & $43 \pm 19(20-89)$ \\
\hline
\end{tabular}

Note.-Unless otherwise specified, data are means \pm standard deviations, with ranges in parentheses. $F V C=$ forced vital capacity, TLC = total lung capacity.

* Data are percentage predicted values.

\section{Table 2}

\section{Pre- and Post-Salbutamol Measurements in 14 Patients}

\begin{tabular}{lcccr} 
Parameter & Pre-Salbutamol & Post-Salbutamol & PValue & \multicolumn{1}{c}{ ES } \\
\hline Pulmonary function measurement (L) & & & & \\
\hline FEV & & & & \\
FVC & $1.23 \pm 0.50$ & $1.35 \pm 0.57)$ & .001 & 0.22 \\
\hline TLC & $2.98 \pm 0.83$ & $3.06 \pm 0.85)$ & .46 & 0.10 \\
\hline Inspiratory capacity & $7.05 \pm 1.22$ & $6.62 \pm 1.26^{\dagger}$ & .04 & -0.35 \\
\hline FRC & $2.15 \pm 0.58$ & $2.02 \pm 0.66^{\dagger}$ & .39 & -0.21 \\
Reserve volume & $4.89 \pm 1.22$ & $4.61 \pm 1.22^{\dagger}$ & .03 & -0.23 \\
Hyperpolarized ${ }^{3}$ He MR imaging & $3.79 \pm 0.91$ & $3.59 \pm 0.85^{\dagger}$ & .23 & -0.23 \\
$\quad$ measurement (\%) & & & & \\
VDP & & & & \\
Cluster 2 & $28 \pm 7$ & $24 \pm 9$ & $<.0001$ & -0.50 \\
Cluster 3 & $15 \pm 2$ & $14 \pm 2$ & .01 & -0.50 \\
\hline Cluster 4 & $31 \pm 5$ & $32 \pm 5$ & .03 & 0.20 \\
Cluster 5 & $19 \pm 4$ & $22 \pm 5$ & $<.0001$ & 0.66 \\
\hline
\end{tabular}

Note.-Unless otherwise specified, data are means \pm standard deviations

* Calculated with repeated-measures analysis of variance for the pulmonary function measurements and two-way mixed-design repeated-measures analysis of variance for the MR imaging measurements.

${ }^{\dagger}$ Available for 13 patients.

(as a region of interest) $(P=.30)$, indicating no bias for any measurable changes with respect to image section. After salbutamol administration, there was a significant decrease in ${ }^{3} \mathrm{He}$ cluster $2(P=.01, \mathrm{ES}=-0.50)$ and significant increases in ${ }^{3} \mathrm{He}$ cluster $3(P=.03$, $\mathrm{ES}=-0.20)$, cluster $4(P<.0001$,
$\mathrm{ES}=-0.66)$, and cluster $5(P=.02, \mathrm{ES}=$ $-0.33)$. On the basis of pre-salbutamol intraobserver variance, the SDD, or the minimum change in ${ }^{3} \mathrm{He}$ measurements that could be measured confidently in individual patients that was not due to observer measurement variability, for five of the patients with COPD (one with stage II disease and four with stage III disease) was $2 \%$ for VDP and $0.4 \%$, $1 \%, 0.6 \%$, and $0.3 \%$ for clusters $2-5$, respectively.

As shown in Figure 3, there were significant and moderate Spearman correlations between baseline ${ }^{3} \mathrm{He}$ VDP and post-salbutamol changes in $\mathrm{FEV}_{1}(r=$ $-0.77, P=.001)$ and between baseline $\mathrm{FEV}_{1}$ as a percentage predicted value and post-salbutamol changes in $\mathrm{FEV}_{1}(r=$ $0.56, P=.04)$. There was also a significant correlation between the changes measured in ${ }^{3} \mathrm{He}$ cluster 2 and changes in $\mathrm{FEV}_{1}(r=-0.62, P=.02)$ and FVC $(r=-0.59, P=.03)$.

\section{Bronchodilator Responders and Nonresponders}

Published ATS and European Respiratory Society guidelines (40) define a significant bronchodilator response as an increase in post-salbutamol $\mathrm{FEV}_{1}$ and/or FVC greater than $200 \mathrm{~mL}$ and $12 \%$. Accordingly, five patients were classified as bronchodilator responders and nine patients were classified as bronchodilator nonresponders. As shown in Table 3 and Table E1 (online), mean reductions in VDP and cluster 2 and corresponding increases in clusters 3-5 were demonstrated for both responders and nonresponders. As shown in Figure 4, VDP was significantly lower for responders than for nonresponders at baseline and after bronchodilator administration $(P=$ .03). As depicted by the parallel slopes for pre- and post-salbutamol measurements shown in Figure 4, there was no significant difference between responders and nonresponders for post-salbutamol change at ${ }^{3} \mathrm{He} \mathrm{MR}$ imaging (VDP, clusters $2-5, P>.05)$. It is important to point out that there was a single nonresponding patient who showed a 240-mL and $12 \%$ improvement in $\mathrm{FEV}_{1}$ (just missing the $>12 \%$ change in $\mathrm{FEV}_{1}$ requirement for bronchodilator 


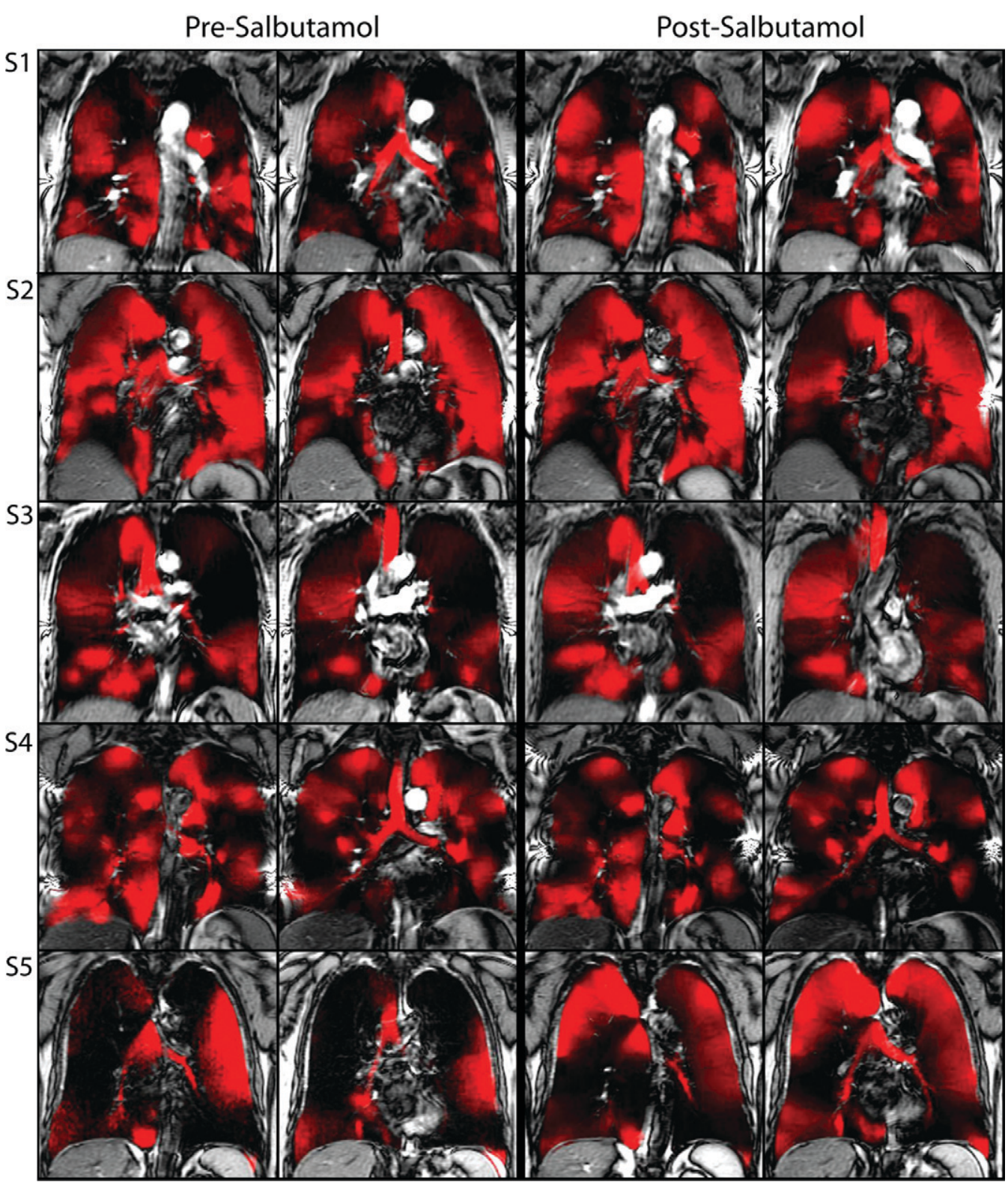

Figure 2: $\quad$ Pre- and post-salbutamol ${ }^{3} \mathrm{He} \mathrm{MR}$ images (in red) registered to two center coronal thoracic ${ }^{1} \mathrm{H}$ MR images (in gray scale) for five representative patients with COPD. The patients in S1 and S2 had GOLD stage II disease, the patients in S3 and $S 4$ had GOLD stage III disease, and the patient in S5 had GOLD stage IV disease. The change in ${ }^{3} \mathrm{He}$ gas distribution after salbutamol is readily apparent in the right and left apical regions in $S 1$ and $S 5$ and in the right mid-apical region in $S 3$, whereas there is little change visible in $S 2$ and $S 4$ for the two sections shown.

response), and when this patient was recategorized as a responder, the reported results remained the same. It is also worth noting that there were no significant differences between responders and nonresponders in terms of baseline $\mathrm{FEV}_{1}(P=.44)$ or DLCO $(P>.99)$.

\section{Discussion}

In this pilot functional MR imaging evaluation of bronchodilator effects in COPD, we made a number of observations and report the following: (a) significant postbronchodilator improvements in both spirometric and ${ }^{3} \mathrm{He}$ MR imaging measurements of gas distribution and their effect sizes, (b) a significant relationship between ${ }^{3} \mathrm{He}$ VDP and changes in $\mathrm{FEV}_{1}$ after salbutamol administration, and (c) changes at ${ }^{3} \mathrm{He} \mathrm{MR}$ imaging after bronchodilator administration that were not significantly different for responder and nonresponder subgroups. 


\section{Figure 3}

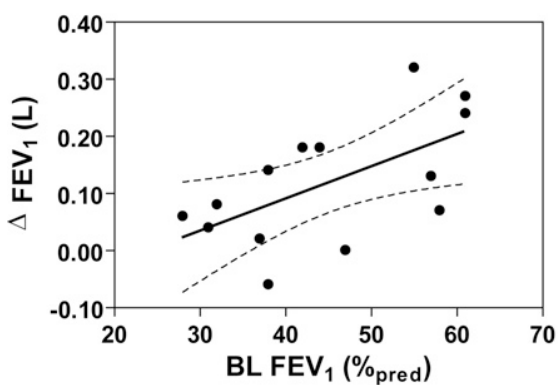

a.

Figure 3: Graphs show correlation between (a) baseline (BL) FEV Fe $_{1}$ as percentage predicted value (\%pred) and post-salbutamol change in FEV (in liters) and (b) baseline VDP and post-salbutamol change in FEV . (a) Baseline $\mathrm{FEV}_{1}$ is significantly correlated with $\Delta \mathrm{FEV}_{1}\left(r=0.60, r^{2}=0.36, P=.02, y=0.006 \cdot-0.13\right)$ and (b) baseline VDP is significantly correlated with $\Delta \mathrm{FEV}_{1}\left(r=-0.68, r^{2}=0.46, P=.008, y=-0.01 \cdot+0.42\right)$. Dotted lines $=95 \%$ confidence intervals.

First, and as might be expected from previous work that demonstrated modest improvements in lung function in patients with COPD after bronchodilator therapy $(7,10,11,41-43)$, we observed statistically significant changes in mean $\mathrm{FEV}_{1}$, FRC, and TLC. At the same time, significant decreases in ${ }^{3} \mathrm{He} \mathrm{MR}$ imaging VDP and cluster 2 and significant improvements in ${ }^{3} \mathrm{He} \mathrm{MR}$ imaging clusters 3-5 were measured, suggesting regional gas distribution improvements throughout the lung. Additionally, the ${ }^{3} \mathrm{He}$ gas distribution changes occurred in different sections for each patient, with no detected bias for specific regions

\section{Figure 4}

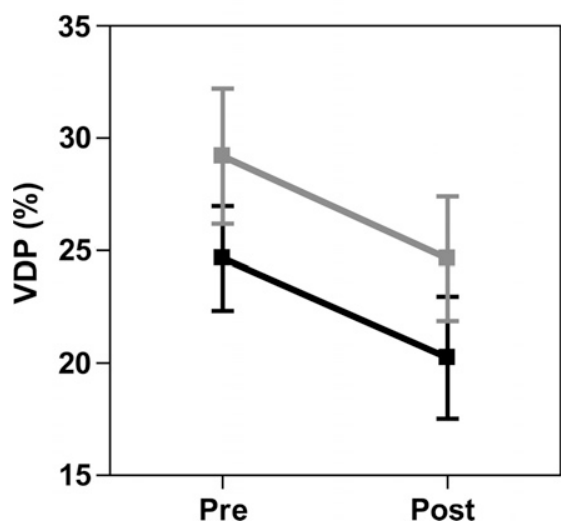

Figure 4: Graph shows mean changes in ${ }^{3} \mathrm{He}$ VDP for bronchodilator responders (black line) and nonresponders (gray line). Values are means calculated for all patient imaging sections, and error bars = 95\% confidence intervals.

of gas distribution improvements. This finding is in agreement with those of a recent CT study (15) that demonstrated regionally dispersed airway wall structural alterations after bronchodilator administration. Moreover, when ES was

\section{Table 3}

Per-Patient Changes in Spirometric and ${ }^{3} \mathrm{He}$ MR imaging Measurements after Salbutamol Administration

\begin{tabular}{|c|c|c|c|c|c|c|c|}
\hline \multirow[b]{2}{*}{ Patient Group and No. } & \multicolumn{2}{|c|}{ Spirometry } & \multicolumn{5}{|c|}{${ }^{3} \mathrm{He}$ MR Imaging } \\
\hline & $\Delta \mathrm{FEV}_{1}^{*}$ & $\Delta \mathrm{FVC}^{*}$ & $\Delta \operatorname{VDP}(\%)$ & $\Delta$ Cluster $2(\%)$ & $\Delta$ Cluster $3(\%)$ & $\Delta$ Cluster $4(\%)$ & $\Delta$ Cluster $5(\%)$ \\
\hline All Patients & $0.12 / 10$ & $0.07 / 2$ & -4 & -1 & 1 & 3 & 1 \\
\hline \multicolumn{8}{|l|}{ Responders } \\
\hline Patient 1 & $0.14 / 11$ & $0.46 / 14$ & 2 & -1 & -1 & 0 & 0 \\
\hline Patient 3 & $0.18 / 16$ & $0.42 / 13$ & 2 & -1 & 0 & 0 & -2 \\
\hline Patient 5 & $0.32 / 15$ & $0.36 / 10$ & -14 & -2 & 2 & 9 & 5 \\
\hline Patient 7 & $0.18 / 25$ & $0.24 / 16$ & 0 & 1 & 1 & 0 & -1 \\
\hline Patient 10 & $0.27 / 22$ & $0.49 / 21$ & -11 & -4 & 4 & 6 & 4 \\
\hline All & $0.22 / 11$ & $0.36 / 14$ & -4 & -1 & 1 & 3 & 1 \\
\hline \multicolumn{8}{|l|}{ Nonresponders } \\
\hline Patient 2 & $0.02 / 2$ & $-0.01 / 0$ & 0 & 0 & 1 & 0 & -1 \\
\hline Patient 4 & $0.04 / 6$ & $-0.25 /-11$ & 2 & -1 & 0 & -1 & -1 \\
\hline Patient 6 & $0.00 / 0$ & $-0.32 /-12$ & 3 & -1 & -2 & 0 & -1 \\
\hline Patient 8 & $-0.06 /-7$ & $-0.07 /-3$ & -6 & -3 & 3 & 5 & 1 \\
\hline Patient 9 & $0.24 / 12$ & $0.35 / 9$ & -2 & 0 & -2 & 2 & 2 \\
\hline Patient 11 & $0.08 / 9$ & $0.11 / 3$ & -8 & 0 & -5 & 9 & 4 \\
\hline Patient 12 & $0.06 / 8$ & $-0.08 /-4$ & -20 & -2 & 10 & 10 & 2 \\
\hline Patient 13 & $0.13 / 9$ & $0.07 / 2$ & -3 & -1 & -1 & 2 & 3 \\
\hline Patient 14 & $0.07 / 4$ & $-0.76 /-17$ & -6 & 1 & 7 & 0 & -2 \\
\hline All & $0.06 / 5$ & $-0.11 /-3$ & -5 & -1 & 1 & 3 & 1 \\
\hline
\end{tabular}

Note.-Significant bronchodilator response was defined as an increase in FEV and/or FVC greater than $200 \mathrm{~mL}$ and $12 \%$ from pre-salbutamol values according to ATS/ European Respiratory Society guidelines (40).

* Data are liters/percentage change from baseline absolute value in liters. 
evaluated, which allows the magnitude of the treatment effect to be compared between disparate types of measurements, ${ }^{3} \mathrm{He}$ MR imaging measurements provided greater ES than $\mathrm{FEV}_{1}$. We also observed an overall mean change in VDP and all ${ }^{3} \mathrm{He}$ ventilation cluster measurements greater than the SDD, indicating that the measured improvement in ${ }^{3} \mathrm{He}$ distribution after salbutamol administration was not due to measurement error or lack of reproducibility. Although this study did not include a control arm, it is important to note that 11 of the 14 patients evaluated here previously participated in a reproducibility study (20) approximately 2 years prior to the preand post-salbutamol imaging in this study. In that previous study, the mean change in VDV for these patients, approximately 7 minutes after imaging, was $1 \mathrm{~mL}-$ not a significant or clinically relevant change. For the same 11 patients reported here, the mean change in ${ }^{3} \mathrm{He}$ VDV (cluster 1) was $62 \mathrm{~mL}$. Taken together, these results strongly suggest that the changes after treatment observed here were not due to either scan-rescan variability or the intraobserver variability of the measurement technique. We must also point out that although, to our knowledge, this is the first reported study demonstrating improvements in ${ }^{3} \mathrm{He}$ gas distribution after bronchodilator therapy in COPD, previous ${ }^{3} \mathrm{He}$ MR imaging studies have demonstrated changes in ${ }^{3} \mathrm{He}$ gas distribution after bronchial provocation tests with methacholine in asthma and after therapy in patients with cystic fibrosis (25-29). Taken together, results of these imaging-based treatment response studies indicate that functional MR imaging may be considered for evaluating new respiratory therapies in clinical trials.

Second, we also observed a significant negative correlation between baseline VDP and changes in $\mathrm{FEV}_{1}$ after salbutamol administration, as well as a significant positive correlation between baseline $\mathrm{FEV}_{1}$ and changes in $\mathrm{FEV}_{1}$. These results suggest that patients demonstrating the greatest improvement in $\mathrm{FEV}_{1}$ after salbutamol administration were those with milder disease. A recent CT study (44) also evaluated a large number of ex-smokers with COPD as part of the National Emphysema Treatment Trial, and, in accordance with our MR imaging results, demonstrated that significant bronchodilator reversibility was more likely in patients with higher FEV .

Finally, we detected postbronchodilator improvements in ${ }^{3} \mathrm{He}$ VDP and gas distribution that were not significantly different for the five responders and nine nonresponders. On the basis of this imaging finding, it appears that even patients with COPD without a clinically relevant improvement in $\mathrm{FEV}_{1}$ show improved regional gas distribution after bronchodilator administration. In fact, both groups showed the same mean improvement in ${ }^{3} \mathrm{He} \mathrm{MR}$ imaging measurements. This important finding suggests that measurements derived from noninvasive imaging reveal functional lung changes that enable a better understanding of the COPD-affected lung and its regional response to therapy, which may be important for drug development and drug treatment trials in COPD. Future functional MR imaging studies with larger sample sizes will help to confirm and extend these important findings.

We acknowledge that this pilot study was limited by the small number of patients examined and by the fact that the analysis was restricted mainly to patients with stage II and III COPD. Therefore, caution should be exercised in extrapolating these results to the general COPD population and more specifically to patients with stage I or IV disease. Another limitation was the lack of a true reference standard for the measurement of treatment effects in COPD, such as dyspnea scores and measurements of exercise tolerance for direct comparison to ${ }^{3} \mathrm{He} \mathrm{MR}$ imaging measurements to evaluate the clinical meaning of the imaging changes. In other words, whether improvements in gas distribution are related to clinical or symptomatic improvement remains to be established in a larger study. It is also important to note that the study patients were provided training and instruction for inspiration breath-hold imaging, and they performed practice breath holds and received coaching during breath-hold MR imaging. It is clear for all imaging studies that standardization is required for reproducible and comparable breath-hold volumes, and this is critically important for acute and chronic therapy repeated studies. We also acknowledge that although ${ }^{3} \mathrm{He}$ MR imaging ventilation defect measurements have been previously reported to have high same-day reproducibility (20) in the majority of patients included in this study, the prospective inclusion of a control group would have strengthened the conclusion that the post-salbutamol changes observed here were directly attributable to bronchodilator treatment. Another important consideration is the limited access to ${ }^{3} \mathrm{He}$ MR imaging and the high cost of ${ }^{3} \mathrm{He}$ gas that has thus far restricted translation of this functional imaging method to specialized MR physics centers. It is important to note the development of hyperpolarized xenon 129 MR imaging, a less expensive and more readily available approach, and a promising alternative against which these reported findings can be directly tested.

In conclusion, our results suggest that noninvasive pulmonary functional ${ }^{3} \mathrm{He}$ MR imaging provides a way to measure acute treatment effects by quantifying ${ }^{3} \mathrm{He}$ gas distribution before and after therapy for COPD.

Acknowledgments: We thank Shayna McKay, BSc, and Sandra Halko, CCRC, RPT, for clinical coordination and clinical database management, Andrew Wheatley, BSc, for production and dispensing of ${ }^{3} \mathrm{He}$ gas, and Yves Bureau, $\mathrm{PhD}$, for assistance with statistical analysis. G.P. gratefully acknowledges helpful discussions and debate with Aaron Fenster, PhD, FCCPM, and the late Peter T. Macklem, MD FRCPC, OC

Disclosures of Potential Conflicts of Interest: M.K. No potential conflicts of interest to dis close. L.M. No potential conflicts of interest to disclose. M.H. No potential conflicts of interest to disclose. R.E. No potential conflicts of interest to disclose. D.G.M. No potential conflicts of interest to disclose. G.P. No potential conflicts of interest to disclose.

\section{References}

1. Rabe KF, Hurd S, Anzueto A, et al. Global strategy for the diagnosis, management, and prevention of chronic obstructive pul monary disease: GOLD executive summary. Am J Respir Crit Care Med 2007;176(6) $532-555$. 
2. Jones PW. Health status measurement in chronic obstructive pulmonary disease. Thorax 2001;56(11):880-887.

3. PauwelsRA, BuistAS, CalverleyPM,Jenkins CR, Hurd SS; GOLD Scientific Committee. Global strategy for the diagnosis, management, and prevention of chronic obstructive pulmonary disease. NHLBI/WHO Global Initiative for Chronic Obstructive Lung Disease (GOLD) Workshop summary. Am J Respir Crit Care Med 2001;163(5):1256-1276.

4. O'Donnell DE, Webb KA. Exertional breathlessness in patients with chronic airflow limitation: the role of lung hyperinflation. Am Rev Respir Dis 1993;148(5):1351-1357.

5. Bauerle O, Chrusch CA, Younes M. Mechanisms by which COPD affects exercise tolerance. Am J Respir Crit Care Med 1998;157(1):57-68.

6. Carlson DJ, Ries AL, Kaplan RM. Prediction of maximum exercise tolerance in patients with COPD. Chest 1991;100(2):307-311.

7. O'Donnell DE, Forkert L, Webb KA. Evaluation of bronchodilator responses in patients with "irreversible" emphysema. Eur Respir J 2001;18(6):914-920.

8. Belman MJ, Botnick WC, Shin JW. Inhaled bronchodilators reduce dynamic hyperinflation during exercise in patients with chronic obstructive pulmonary disease. Am J Respir Crit Care Med 1996;153(3):967-975.

9. O'Donnell DE, Lam M, Webb KA. Measurement of symptoms, lung hyperinflation, and endurance during exercise in chronic obstructive pulmonary disease. Am J Respir Crit Care Med 1998;158(5 Pt 1):1557-1565.

10. Costa GM, Faria AC, Di Mango AM, Lopes AJ, Jansen JM, Melo PL. Bronchodilation in COPD: beyond FEV1-the effect of albuterol on resistive and reactive properties of the respiratory system. J Bras Pneumol 2009; 35(4):325-333

11. Borrill ZL, Houghton CM, Tal-Singer R, et al. The use of plethysmography and oscillometry to compare long-acting bronchodilators in patients with COPD. Br J Clin Pharmacol 2008;65(2):244-252.

12. De Luca N, Capuzi P, D’Angeli AL, et al. High resolution computed tomography (HRCT) assessment of beta 2-agonist induced bronchodilation in chronic obstructive pulmonary disease patients. Eur Rev Med Pharmacol Sci 1999;3(2):83-87.

13. Cerveri I, Pellegrino R, Dore R, et al. Mechanisms for isolated volume response to a bronchodilator in patients with COPD. J Appl Physiol 2000;88(6):1989-1995.

14. Gelb AF, Taylor CF, Cassino C, Shinar CM, Schein MJ, Zamel N. Tiotropium induced bronchodilation and protection from dynamic hyperinflation is independent of extent of emphysema in COPD. Pulm Pharmacol Ther 2009;22(3):237-242.

15. Hasegawa M, Makita H, Nasuhara Y, et al Relationship between improved airflow limitation and changes in airway calibre induced by inhaled anticholinergic agents in COPD. Thorax 2009;64(4):332-338.

16. Lee JH, Lee YK, Kim EK, et al. Responses to inhaled long-acting beta-agonist and corticosteroid according to COPD subtype. Re spir Med 2010;104(4):542-549.

17. Diba C, Salome CM, Berend N, Harris B, Bailey D, King GG. Effect of bronchodilator on ventilation heterogeneity in COPD [abstr]. Am J Respir Crit Care Med 2009;179:A5577.

18. Kirby M, Mathew L, Wheatley A, Santyr GE, McCormack DG, Parraga G. Chronic obstructive pulmonary disease: longitudinal hyperpolarized (3)He MR imaging. Radiology 2010;256(1):280-289.

19. Mathew L, Kirby M, Etemad-Rezai R, Wheatley A, McCormack DG, Parraga G. Hyperpolarized (3)He magnetic resonance imaging: preliminary evaluation of phenotyping potential in chronic obstructive pulmonary disease. Eur J Radiol 2011;79(1):140-146.

20. Mathew L, Evans A, Ouriadov A, et al. Hyperpolarized $3 \mathrm{He}$ magnetic resonance imaging of chronic obstructive pulmonary disease: reproducibility at 3.0 tesla. Acad Radiol 2008;15(10):1298-1311.

21. Parraga G, Ouriadov A, Evans A, et al Hyperpolarized $3 \mathrm{He}$ ventilation defects and apparent diffusion coefficients in chronic obstructive pulmonary disease: preliminary results at 3.0 Tesla. Invest Radiol 2007;42(6): 384-391.

22. Mathew L, Gaede S, Wheatley A, EtemadRezai R, Rodrigues GB, Parraga G. Detection of longitudinal lung structural and functional changes after diagnosis of radiation-induced lung injury using hyperpolarized $3 \mathrm{He}$ magnetic resonance imaging. Med Phys 2010; $37(1): 22-31$.

23. Evans A, McCormack DG, Santyr G, Parraga G Mapping and quantifying hyperpolarized $3 \mathrm{He}$ magnetic resonance imaging apparent diffusion coefficient gradients. J Appl Physiol 2008; 105(2):693-699.

24. Woodhouse N, Wild JM, Paley MN, et al. Combined helium-3/proton magnetic resonance imaging measurement of ventilated lung volumes in smokers compared to neversmokers. J Magn Reson Imaging 2005;21(4): 365-369.

25. de Lange EE, Altes TA, Patrie JT, et al. Changes in regional airflow obstruction over time in the lungs of patients with asthma: evaluation with $3 \mathrm{He}$ MR imaging. Radiology 2009;250(2):567-575.

26. de Lange EE, Altes TA, Patrie JT, et al. The variability of regional airflow obstruction within the lungs of patients with asthma: assessment with hyperpolarized helium-3 magnetic resonance imaging. J Allergy Clin Immunol 2007;119(5):1072-1078.

27. Samee S, Altes T, Powers P, et al. Imaging the lungs in asthmatic patients by using hyperpolarized helium-3 magnetic resonance: assessment of response to methacholine and exercise challenge. J Allergy Clin Immunol 2003;111(6): 1205-1211.

28. Mentore K, Froh DK, de Lange EE, Brookeman JR, Paget-Brown AO, Altes TA. Hyperpolarized HHe 3 MRI of the lung in cystic fibrosis: assessment at baseline and after bronchodilator and airway clearance treatment. Acad Radiol 2005;12(11): 1423-1429.

29. Woodhouse N, Wild JM, van Beek EJ, Hoggard N, Barker N, Taylor CJ. Assessment of hyperpolarized 3He lung MRI for regional evaluation of interventional therapy: a pilot study in pediatric cystic fibrosis. J Magn Reson Imaging 2009;30(5):981-988.

30. Koumellis P, van Beek EJ, Woodhouse N, et al. Quantitative analysis of regional airways obstruction using dynamic hyperpolarized 3He MRI-preliminary results in children with cystic fibrosis. J Magn Reson Imaging 2005;22(3):420-426.

31. Heydarian M, Kirby M, Choy S, et al. Semiautomated segmentation of pulmonary ventilation using hyperpolarized ${ }^{3} \mathrm{He}$ magnetic resonance imaging [abstract]. Biomedical Engineering Society Annual Meeting 2010: Imaging the Lung - The New Frontier. Austin, Texas: Biomedical Engineering Society, 2010; 82 .

32. MacQueen J. Some methods for classification and analysis of multivariate observations. In: Le Cam LM, Neyman J, eds. Fifth Berkeley Symposium on Mathematical Statistics and Probability: Statistical Laboratory of the University of California, Berkeley. Berkeley, Calif: University of California Press, 1967; 281-297.

33. Cooley B, Acton S, Salerno M, et al. Automated scoring of hyperpolarized helium-3 MR lung ventilation images: initial development and validation (abstr). In: Proceedings of the Tenth Meeting of the International Society for Magnetic Resonance in Medicine. Berkeley, Calif: International Society for Magnetic Resonance in Medicine.

34. Ray N, Acton ST, Altes T, de Lange EE, Brookeman JR. Merging parametric active contours within homogeneous image regions 
for MRI-based lung segmentation. IEEE Trans Med Imaging 2003;22(2):189-199.

35. Guyer RA, Hellman MD, Emami K, et al. A robust method for estimating regional pulmonary parameters in presence of noise. Acad Radiol 2008;15(6):740-752.

36. Adams R, Bischof L. Seeded region growing. IEEE Trans Pattern Anal Mach Intell 1994;16(6):641-647.

37. Kirby M, Wheatley A, McCormack DG, Parraga G. Development and application of methods to quantify spatial and temporal hyperpolarized 3He MRI ventilation dynamics: preliminary results in chronic obstructive pulmonary disease. In: Molthen RC, Weaver JB, eds. Proceedings of SPIE: medical imaging 2010: Biomedical Applications in Molecular,
Structural, and Functional Imaging. Vol 7626. Bellingham, Wash: International Society for Optical Engineering, 2010; 762601.

38. Hedges LV. Distribution theory for Glass's estimator of effect size and related estimators. J Educ Behav Stat 1981;6(2):107-128.

39. Eliasziw M, Young SL, Woodbury MG, Fryday-Field K. Statistical methodology for the concurrent assessment of interrater and intrarater reliability: using goniometric measurements as an example. Phys Ther 1994; 74(8):777-788.

40. Pellegrino R, Viegi G, Brusasco V, et al. Interpretative strategies for lung function tests. Eur Respir J 2005;26(5):948-968.

41. Rubin AS, Souza FJ, Hetzel JL, Moreira Jda S. Immediate bronchodilator response to formoterol in poorly reversible chronic obstructive pulmonary disease [in Portuguese]. J Bras Pneumol 2008;34(6):373-379.

42. O'Donnell DE, Revill SM, Webb KA. Dynamic hyperinflation and exercise intolerance in chronic obstructive pulmonary disease. Am J Respir Crit Care Med 2001;164(5):770-777.

43. Jensen D, Amjadi K, Harris-McAllister V, Webb KA, O'Donnell DE. Mechanisms of dyspnoea relief and improved exercise endurance after furosemide inhalation in COPD. Thorax 2008;63(7):606-613.

44. Han MK, Wise R, Mumford J, et al. Prevalence and clinical correlates of bronchoreversibility in severe emphysema. Eur Respir J 2010;35(5):1048-1056. 